\title{
Performance estimation of Different controller for the Industrial Based Process
}

\author{
H.Kala $^{1}$, P.Sathiya ${ }^{2}$, G.Vijayalakshmi ${ }^{3}$ \\ Assistant Professor, Department of ICE, Saranathan College of Engineering, Trichy, India ${ }^{1,2,3}$
}

\begin{abstract}
Most of the processes used in the industry are First Order plus Dead Time process. Blending Process is chosen and FOPDT model is designed for the process, Different controller technique is tuned for the given process. The controllers are compared with time domain specification and Performance indices. The optimal controller for the process is chosen with minimum time domain specification and minimum performance indices.
\end{abstract}

Keywords: FOPDT, Dead-time, Time domain specification, Performance indices.

\section{INTRODUCTION}

Many industries are comprised of first order plus dead A stirred tank blending is chosen for the process which has time. The process taken here is blended process, which a Stream 1 , which is a mixture of two chemical process of combing materials, in which solid-solid or components $\mathrm{A}$ and $\mathrm{B}$, the mass flow rate of stream 1 is $\mathrm{w}_{1}$ mixing of bulk solids with small quantity of liquid are which is constant and the mass fraction of stream 1 is $\mathrm{x}_{1}$ taken place. This blending process is used in many which varies with time. Stream 2 is a pure form of mixture chemical industries. In chemical industries the process of $\mathrm{A}$ which is a mass flow rate of $\mathrm{w}_{2}$ and mass fraction of mixing two components with equal percentage is taking stream 2 is $x_{2}=1$. The mass fraction of the final output is place, where higher order model are obtained during this denoted by $\mathrm{x}$ and the desired value is reached.

process. This was a tedious process in controlling process model, Therefore this higher order process model is modelled as a linear first order process with dead time. In real time world first order process with dead time is controlled using PID controller, because we get minimum time delay and minimum overshoot. Various methods have been established for PID controller, As a result the Different PID control tuning is compared with Model Predictive Controller (MPC) and the best controller is chosen with minimum time domain specification and minimum performance indices.

\section{PROCESS SETUP}

\section{A. Description of Process}

Chemical industry uses blending process as one of the main process. Blending process is taken as process and the process modelling for the blending process is designed.

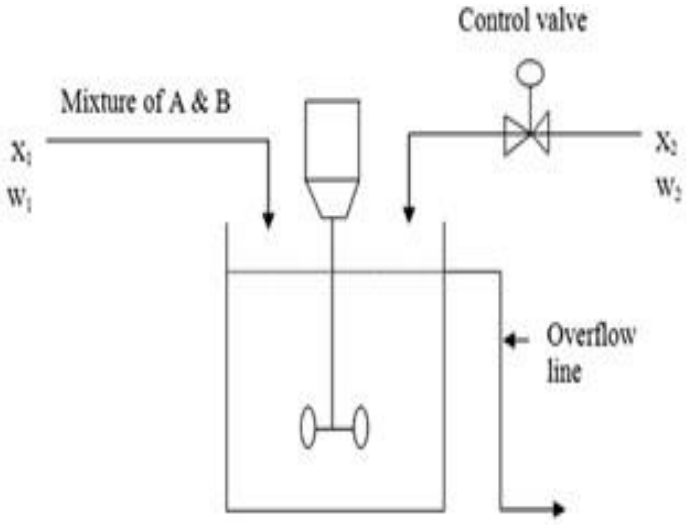

Fig 1. Process setup

\section{III.CONTROLLER DESIGN}

In many industries PID controller is implemented for controlling the real time process. In this process different types of PID controller are implemented and compared with MPC, in terms of Performance indices and Time domain specification. First order plus dead time process modelling is obtained by using Process Reaction Curve method. The transfer function for the process is obtained.

The PID controllers implemented in the process are defined below.

\section{A. Connell et al}

It was invented by Connell in the year 1996, in which the overshoot of the process is reduced using this Connell PID controller.

\begin{tabular}{|l|c|c|c|}
\hline Controller & $K_{p}$ & $\tau_{I}$ & $\tau_{d}$ \\
\hline PID & $\frac{1.6 T_{m}}{K_{m} \tau_{m}}$ & $1.6667 \tau_{m}$ & $0.4 \tau_{m}$ \\
\hline
\end{tabular}

Table 1. Connell et al formula

\section{B. Callender et al}

It was invented in the year 1935, which was the first PID controller invented by Callender. It reduces $0.3 \%$ of overshoot from the desired output.

\begin{tabular}{|l|c|c|c|}
\hline Controller & $K_{p}$ & $\tau_{I}$ & $\tau_{d}$ \\
\hline PID & $\frac{1.6 T_{m}}{K_{m} \tau_{m}}$ & $1.418 \tau_{m}$ & $0.353 \tau_{m}$ (or) $0.47 \tau_{m}$ \\
\hline
\end{tabular}

Table 2. Callender et al formula

\section{Chinn et al}

It was introduced by Chinn in the year 1952, which is used to reduce the regulatory problem in the Process, it has $0 \%$ Overshoot and it is most widely used in many processes 
INTERNATIONAL JOURNAL OF INNOVATIVE RESEARCH IN ELECTRICAL, ELECTRONICS, INSTRUMENTATION AND CONTROL ENGINEERING Vol. 4, Issue 1, January 2016

\begin{tabular}{|l|c|c|c|}
\hline Controller & $K_{p}$ & $\tau_{I}$ & $\tau_{d}$ \\
\hline PID & $\frac{0.95 T_{m}}{K_{m} \tau_{m}}$ & $2.387 \tau_{m}$ & $0.42 \tau_{m}$ \\
\hline
\end{tabular}

Table 4. Chinn et al formula

\section{Astrom \& Hugg}

Astrom \& Hugg invented a new method to tune PID controller,In which the oveshoot is minimum when compared other PID controllers

\begin{tabular}{|l|c|c|c|}
\hline Controller & $K_{p}$ & $\tau_{I}$ & $\tau_{d}$ \\
\hline PID & $\frac{3}{K_{m}}$ & $T_{90 \%}$ & $0.5 \tau_{m}$ \\
\hline
\end{tabular}

Table 5. Amstrong \& Hugg formula

\section{E. Modern Predictive Controller (MPC)}

(MPC) is an superior method of process control that has been in use in the process industries in chemical plants and oil refineries etc. It is used to predict the future evolution of the process to optimize the control signal. The main advantage of MPC is the fact that it allows the current timeslot to be optimized, while keeping future timeslots in account. This is achieved by optimizing a finite time-horizon, but only implementing the current timeslot.

It is based on iterative based technique, in which the current state is sampled and a cost minimizing control strategy is computed, for a relatively short time horizon $(t$, $\mathrm{t}+\mathrm{T})$, Then the plant is sampled again and the new state for the plant is identified, obtaining a new control and new prediction state path.

The reason for MPC having receding horizon is that the prediction horizon keeps on shifting forwarding.

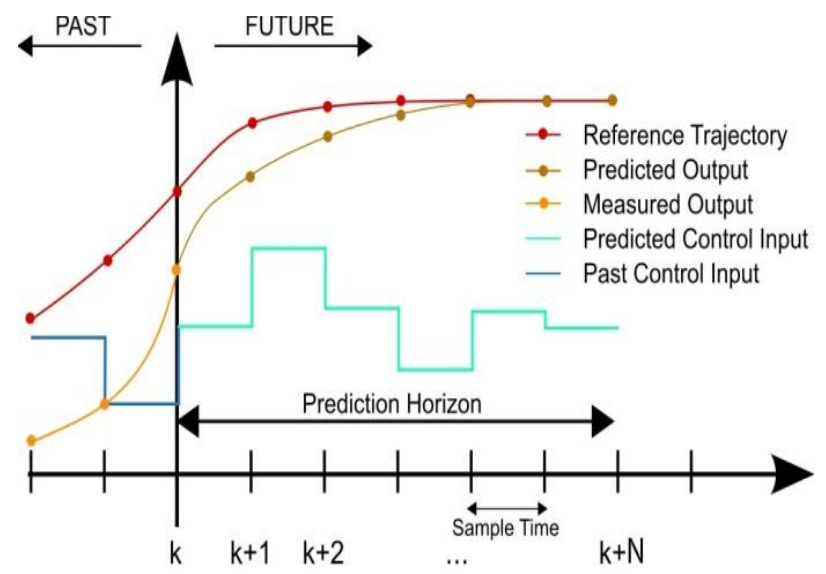

Fig 2. Modern predictive control

\section{IV.RESULT AND DISCUSSION}

The process chosen here is blending process, in which FOPDT process is obtained. A different type of PID controller is tuned for the given process with MPC controller. The controller that has minimum time domain specification \& minimum performance indices is selected as the best controller for the process.

The time domain specification \& performance indices are tabulated in Table $1 \&$ Table 2.

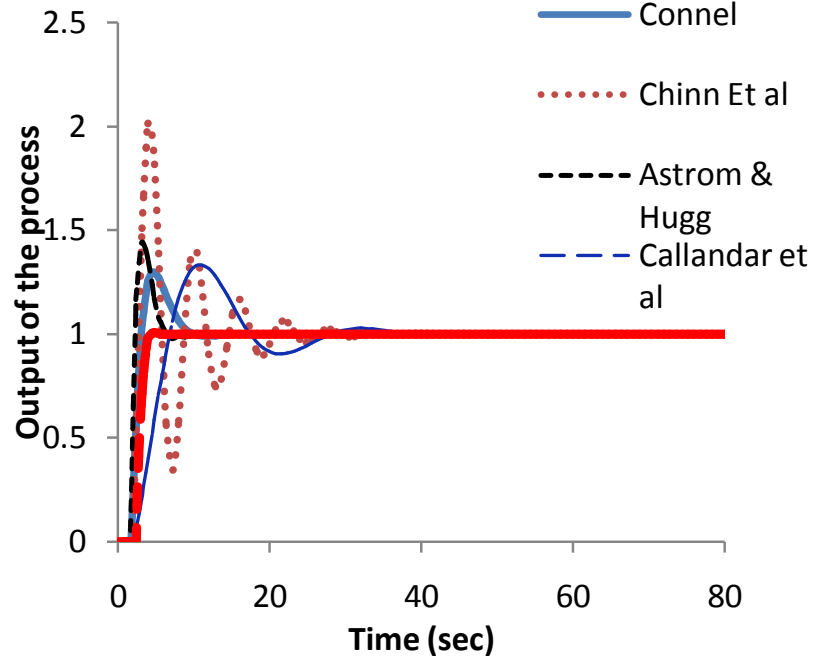

Fig 3. Comparison of Different controller for a stirred tank blending process

\begin{tabular}{|l|c|c|c|}
\hline Controller & $\begin{array}{c}\text { Rise } \\
\text { Time }\end{array}$ & $\begin{array}{c}\text { Settling } \\
\text { Time }\end{array}$ & $\begin{array}{c}\text { Peak } \\
\text { Overshoot }\end{array}$ \\
\hline $\begin{array}{l}\text { Astrom \& } \\
\text { Hugg }\end{array}$ & 3.7 & 18 & 0.29 \\
\hline Chinn et al & 2.7 & 45 & 1 \\
\hline Connel et al & 2.4 & 25 & 0.4 \\
\hline $\begin{array}{l}\text { Callender et } \\
\text { al }\end{array}$ & 6.8 & 60 & 0.35 \\
\hline MPC & 2 & 5 & 0 \\
\hline
\end{tabular}

Table 6. Time domain specification for the blending process

\begin{tabular}{|l|l|l|l|l|}
\hline Controller & IAE & ISE & ITAE & MSE \\
\hline $\begin{array}{l}\text { Astrom \& } \\
\text { Hugg }\end{array}$ & 19.28 & 13.59 & 36.67 & 0.1346 \\
\hline Chinn et al & 51.20 & 36.10 & 467.69 & 0.3575 \\
\hline $\begin{array}{l}\text { Connel et } \\
\text { al }\end{array}$ & 16.91 & 18.92 & 19.384 & 0.1874 \\
\hline $\begin{array}{l}\text { Callender } \\
\text { et al }\end{array}$ & 42.82 & 28.08 & 490.37 & 0.2761 \\
\hline MPC & 23.91 & 20.08 & 23.96 & 0.1011 \\
\hline
\end{tabular}

Table 7. Performance indices for the blending process

\section{CONCLUSION}

It is evident that from Table $1 \&$ Table 2, MPC controller has better performance when compared to all other controller in terms of Time domain specification \& Performance indices. Therefore MPC is the better chosen controller for the process. In future Neutral Network, ANFIS, Fuzzy Logic Controller is implemented for the process.

\section{REFERENCES}

[1] Kurtulan,S., Goren, L., "A design method for a wide class of industrial processes", Turkish Automatic Control Committee National Congress, October, 2005 (In Turkish).

[2] O"Dwyer, A., "PID compensation of time delayed processes 19982002: a survey", in Proc. American Control Conf., Denver, Colorado, USA, pp. 1494-1499, 2003.

[3] Astrom, K. J., and Hagglund, T., Automatic Tuning of PID Controllers, Instrument Society of America, 1998. 
[4] Koivo, H. N., and Tanttu, J. T., "Tuning of PID Controllers: Survey of SISO and MIMO Techniques," in Proceedings of Intelligent Tuning and Adaptive Control, Singapore, 1991

[5] William S. Levine, W.S (Editor), CRC Control Handbook, Chapter 72, "Control of the Pulp and Paper Making Process". CRC Press and IEEE Press, - Bialkowski W., Chapter 72, 1996.

[6] William S. Levine, W.S (Editor), CRC Control Handbook, Chapter 72, "Control of the Pulp and Paper Making Process". CRC Press and IEEE Press, - Bialkowski W., Chapter 72, $1996 .$.

[7] Dan Chen and Seborg, Dale E., "PI/PID Controller Design Based on Direct Synthesis and Disturbance Rejection", Ind. Eng. Chen. Res 2004, 41, pp. 4807-4822.

[8] Tavakoli Saeed \& Tavakoli Mahdi "Optimal tuning of PID controller for first order plus delay models using dimensional" The Fourth International Conference on Control and Automation (ICCA"03), Montreal, Canada, 10-12 June 2003.

[9] Nazreen Banu.A, Nivethitha.I.S, Nisha.A, Kala.H, Nithyarani.N,"Evaluation of diverse controller Strategic for a level process" International Journal Of Innovative Research In Electrical, Electronics, Instrumentation And Control Engineering,Vol. 2, Issue 8,August 2014.

[10] A.Thamemul Ansari, K.Thivakaran, K.Tharani Raja, H.Kala, S.Abirami, "Modelling and Controlling the Level of Nonlinear Process via Diverse Control Strategies", International Journal of Advanced Research in Electrical, Electronics and Instrumentation Engineering,Vol. 3,Issue 9, September 2014.

[11] B.Suganya, P Sandi, H.Kala, R.Suresh Kumar, V.Sabari, "Controlling the Level of Linear Process Using Different PID Technique" Vol. 4, Issue 9, September 2015.

[12] H. Kala, S. Abirami, S. Muthumari and S. Venkatesh, "Model Identification and comparision of different controller for humidity process", Journal of applied scinces, pp. 1570-1575, Vol. 14, Issue. 14,2012

[13] H. Kala, "Implementation of System Identification and Comparison of Ziegler-Nichols and Genetic Algorithm Moisture Process", IJIREEICE, Vol. 1, Issue. 9, 2013, Impact Factor : 1.112

[14] H. Kala, "Performance evaluation of diverse controller for Flow process", IJSETR, pp. 534-537, Vol. 3, Issue. 3, 2014.

\section{BIOGRAPHIES}

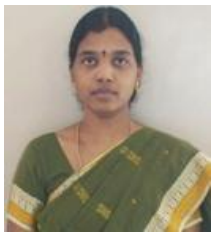

G. Vijayalakshmi received her B.E. degree in in Electronics and Instrumentation Engineering in 2005 from Shri Angalamman college of engineering, Trichy, Affiliated to Anna University Chennai, and M.E. in power electronics and drives in 2014 from Saranathan college of Engineering, Trichy, Affliliated to Anna University Chennai. Her area of interest is in power electronic controllers and PLC.

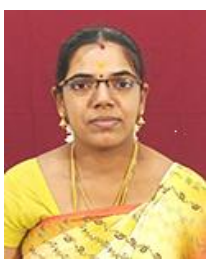

H.Kala completed her Bachelor of Engineering in 2011 from Saranathan College of Engineering. After that she received her Master in Technology from SASTRA University, Thanjavur in the year 2013. Her area of interest is Process Control, Soft Computing Techniques,

Image Processing.

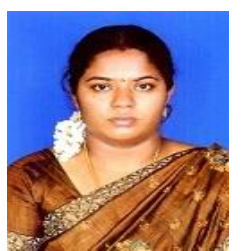

P.Sathiya completed her Bachelor of Engineering in 2010 at JJ College of Engineering,Trichy. she received her Master of engineering at SHIVANI College of engineering, Trichy in the year 2014. Her area of interest is Power electronics \& drives, Control systems,Biomedical instrumentation 